\title{
REFLECTION
}

\section{From Transactional Tasks to Personalized Care: A New Vision of Physicians' Roles}

\author{
David B. Reuben, MD \\ Christine A. Sinsky, MD \\ 'Division of Geriatrics, David Geffen \\ School of Medicine at UCLA, Los Angeles, \\ California \\ ${ }^{2}$ American Medical Association, Chicago, \\ Illinois
}

Ann Fam Med 2018;16:168-170. https://doi.org/10.1370/afm.2203.

$\mathrm{n}$ the past quarter century, changes in the health care environment have dramatically affected both physician roles and physicians' satisfaction. ${ }^{1}$ Among the most important changes have been the shift in emphasis from acute to chronic illness care, the increased percentage of physicians who are employed by large medical groups and health systems, the exodus of many physicians from hospital care, the increase in patient access to health information (eg, via the Internet), and the introduction of the electronic health record (EHR), which has changed the work of physicians well beyond the documentation of clinical care.

In addition to these macro changes, physicians cite time pressures, chaotic work environments, lack of control over the workday, additional clerical work imposed by the EHR, and taking on rote, mandatory care processes that are disconnected from the needs of patients as factors contributing to career dissatisfaction. ${ }^{2}$ As a result, the majority of physicians now exhibit signs of burnout. ${ }^{3}$

There is a gap between the professional mission physicians want to do (caring relationships with patients, using intellectual and technical skills to help people, autonomy in their daily work) and what physicians spend a substantial portion of their time and energy doing (data entry and forced function work). ${ }^{4}$ We believe that by taking steps to close this gap, physicians will again be able to find joy, purpose, and meaning in their profession and give back what patients and society need from 21st-century physicians.

A new vision for optimizing physician contributions to health care would begin with recrafting roles of physicians to better fit the evolving health care ecosystem. Physicians should play a smaller role in "transactional" aspects of care (Table 1), such as providing most guideline care for preventive services, data gathering and entry, and documentation. In general, these functions can be performed by other clinical professionals and staff who have less training. Physicians' roles in these transactional

\begin{abstract}
Changes in health care delivery have affected the work that physicians are
expected to perform and, in turn, their satisfaction. There is a gap between the
professional mission - what physicians want to do (eg, caring relationships with
patients, using intellectual and technical skills to help people, autonomy in their
ABSTRACT
Changes in health care delivery have affected the work that physicians are
expected to perform and, in turn, their satisfaction. There is a gap between the
professional mission-what physicians want to do (eg, caring relationships with
patients, using intellectual and technical skills to help people, autonomy in their

ABSTRACT
Changes in health care delivery have affected the work that physicians are
expected to perform and, in turn, their satisfaction. There is a gap between the
professional mission-what physicians want to do (eg, caring relationships with
patients, using intellectual and technical skills to help people, autonomy in their

ABSTRACT
Changes in health care delivery have affected the work that physicians are
expected to perform and, in turn, their satisfaction. There is a gap between the
professional mission-what physicians want to do (eg, caring relationships with
patients, using intellectual and technical skills to help people, autonomy in their

ABSTRACT
Changes in health care delivery have affected the work that physicians are
expected to perform and, in turn, their satisfaction. There is a gap between the
professional mission-what physicians want to do (eg, caring relationships with
patients, using intellectual and technical skills to help people, autonomy in their daily work) and what physicians spend a substantial portion of their time and energy doing (eg, data entry and forced function work). We believe that steps can be taken to align the current and future practice of medicine with the professional mission that motivates physicians and creates satisfaction. These steps focus on shifting physicians' responsibilities away from transactional tasks and towards personalized aspects of care. By taking steps to close the gap between mission and daily work, physicians will again be able to find joy, purpose, and meaning in their profession and give back what patients and society need from 21st century physicians
\end{abstract}

David B. Reuben, MD

David Geffen School of Medicine at UCLA, Division of Geriatrics 10945 Le Conte Avenue, Suite 2339 Los Angeles, CA 90095-1687 dreuben@mednet.ucla.edu 
functions might include developing local guidelines and protocols, serving as content experts, and leading clinical teams.

By relinquishing transactional tasks, physicians will be able to play a larger role in the "personalized" aspects of health care (Table 1): customizing care for individual patients by synthesizing data from diverse, often discordant sources; adjudicating competing needs of multiple conditions; adjusting the treatment plan to align with patient's personal preferences and goals, and working together with colleagues regarding mutual patients. Physicians are experts in making diagnoses and initiating successful treatment (which may be implemented by other health professionals), including performing needed procedures, and using clinical judgment to determine the optimal path forward for any individual patient. Physicians are skilled in determining patient objectives and reconciling these with the medical realities of what is possible. Physicians can also be the most effective advocates for individual patients in a complicated, fragmented health care environment.

Although transactional and personalized aspects of care are conceptually distinct, in practice there is some overlap. Physicians may need to perform some transactional functions that require shared decision making, such as deciding whether to screen for prostate cancer. Although there are some transactional aspects of the technical components of procedures, deciding whether and when to perform procedures, the nuances of procedures themselves, and managing complications are personalized care. Despite some exceptions, the overlying construct of distinguishing routine transactional functions from those that need to be personalized provides a framework for how health care organizations and physicians can determine whether tasks should be primarily the physician's responsibility. Of note, identifying personalized aspects of health care and having only these tasks performed by the highest qualified professional is not unique to physicians. Many other professions, such as nursing, pharmacy, and physical therapy have delegated transactional aspects of care to "assistants" working with their professions.

To make the switch from providing transactional care to personalized care, changes are needed at all levels: medical education, individual physician, delivery organization, technology tools, policy, and payment. Medical educators will need to teach physicians additional personalized care skills that have been lacking in the current curriculum. These include better oral and written communication skills for caring for patients to determine personal health-related goals and negotiate treatment plans, and interacting with colleaguesboth physicians and other members of the health care team-to ensure that everyone is working on common
Table 1. Transactional and Personalized Aspects of Patient Care

\begin{tabular}{|c|c|}
\hline Transactional & Personalized \\
\hline Data gathering and entry & Synthesizing data from diverse sources \\
\hline Most preventive care ${ }^{a}$ & Customizing care for individual patients \\
\hline $\begin{array}{l}\text { Guideline-based disease } \\
\text { management }^{\mathrm{a}}\end{array}$ & $\begin{array}{l}\text { Adjudicating competing needs of mul- } \\
\text { tiple conditions }\end{array}$ \\
\hline $\begin{array}{l}\text { Disease-specific patient } \\
\text { education }\end{array}$ & $\begin{array}{l}\text { Negotiating individual treatment } \\
\text { plans and agreeing upon expected } \\
\text { outcomes }\end{array}$ \\
\hline Documentation of care & $\begin{array}{l}\text { Performing procedures and managing } \\
\text { complications }\end{array}$ \\
\hline $\begin{array}{l}\text { Coding, billing, and prior } \\
\text { authorization tasks }\end{array}$ & Advocating for individual patients \\
\hline \multicolumn{2}{|c|}{$\begin{array}{l}\text { a Some preventive care and guideline-based disease management require } \\
\text { shared decision making (eg, screening for prostate cancer, choice of medica- } \\
\text { tion) and are therefore personalized care. }\end{array}$} \\
\hline
\end{tabular}

goals and that the workload of transactional and personalized aspects of care is distributed appropriately.

Physicians will need to embrace team care by engaging other health care professionals who bring complementary skills and by being willing to delegate care processes to them to create a shared model of care. Too often, team care is compromised because physicians cannot or do not share aspects of care with others because of cultural, organizational, regulatory, or technology barriers that force physicians to perform transactional tasks. In their roles as leaders in health care organizations, physicians also need to think systematically, including redesigning practice to fix workflow inefficiencies, creating new types of health care personnel or recrafting responsibilities of existing personnel to complete the transactional work of patient care, and harnessing technology to reduce human time and effort. Finally, physicians need to develop leadership skills that extend beyond coercing and pacesetting styles to those that emphasize motivating others, creating emotional bonds, and coaching. ${ }^{5}$

Health care organizations need to support staffing ratios and levels of training that allow physicians to focus on personalized aspects of care while trusting in the safety and quality of work, both personalized and transactional, done as a team. Technology and policies need to be constructed to promote teamwork, for example, by permitting, directing, and facilitating administrative transactional tasks like billing, coding, order entry, and documentation tasks to be completed by staff.

EHRs will also need to change to help physicians in their work and ensure that medical records are valuable in caring for patients, for example, by prominently displaying a shared care plan, indicating tasks and milestones, designating transactional and personalized responsibilities of various team members, and facilitating live conversations between colleagues. 
At a policy level, measures of accountability need to recognize physicians' unique roles in personalized aspects of care rather than relying on performance measures of transactional functions. These performance measures should also be ones that individual physicians have power to affect rather than those that are dependent upon organizational or patient factors. Focusing accountability on these meaningful responsibilities will be a powerful way to both engage physicians and improve professional fulfillment by tapping into the internal motivation that is driven by autonomy, mastery, and purpose. ${ }^{6,7}$ Finally, in spite of the inherent difficulty in quantifying performance in providing customized care for patients, payment systems must be revised to appropriately compensate physicians for personalized aspects of care within and outside the visit.

It is clearly in society's broader interest for medicine to remain a desirable profession that attracts the best and brightest. Achieving that goal will require that roles be redesigned to assure that physicians perform and are held accountable for work that is at the appropriate level for physicians. Physicians of the future will need to be adequately trained in the knowledge and skills to do this work and health care environments, policies, and payment will need to change to support the roles of physicians of the 21st century. Making the shift from current unfulfilling transactional roles to focus on the great value inherent in providing personalized aspects of care will be a triple win-for patients, physicians, and society.
To read more or post commentaries in response to this article, see it online at http://www.AnnFamMed.org/content/16/2/168.

Key words: physician burnout; physician's roles; health care reform; physician satisfaction

Submitted August 18, 2017; submitted, revised, October 30, 2017; accepted November 29, 2017.

\section{References}

1. Shanafelt TD, Gorringe G, Menaker R, et al. Impact of organizational leadership on physician burnout and satisfaction. Mayo Clin Proc. 2015;90(4):432-440.

2. Friedberg MW, Chen PG, Van Busum KR, et al. Factors Affecting Physician Professional Satisfaction and Their Implications for Patient Care, Health Systems, and Health Policy. Santa Monica, CA: RAND Corporation; 2013. http://www.rand.org/pubs/research_reports/RR439.html.

3. Shanafelt TD, Hasan O, Dyrbye LN, et al. Changes in burnout and satisfaction with work-life balance in physicians and the general US working population between 2011 and 2014. Mayo Clin Proc. 2015: 90(12):1600-1613.

4. Sinsky C, Colligan L, Li L, et al. Allocation of physician time in ambulatory practice: a time and motion study in 4 specialties. Ann Intern Med. 2016;165(11):753-760.

5. Goleman D. Leadership that gets results. Harv Bus Rev. 2000; 78(2): 78-90.

6. Pink DH. Drive: The Surprising Truth About What Motivates Us. New York, NY: Riverhead Books; 2009.

7. Cassel CK, Jain SH. Assessing individual physician performance: does measurement suppress motivation? JAMA. 2012;307(24): 2595-2596. 